\title{
UM ESTUDO SOBRE OS FATORES QUE INFLUENCIAM NO DESENVOLVIMENTO DE COMPETÊNCIAS EMPREENDEDORAS
}

\section{AN STUDY ABOUT THE INFLUENCE FACTORS ON THE DEVELOPMENT OF ENTREPRENEURIAL COMPETENCES}

Teodoro Malta Campos

Faculdade de Ciências Sociais Aplicadas do Sul de Minas (FACESM).

Itajubá, MG, Brasil.

Email: teodoromalta@gmail.com

\section{Edmilson de Oliveira Lima}

Professor no Programa de Pós-Graduação em Administração (PPGA - mestrado e doutorado) da Universidade Nove de Julho - UNINOVE São Paulo, SP, Brasil.

Email: edmilsonolima@gmail.com

\section{RESUMO}

Este estudo tem por finalidade identificar e compreender os fatores que favorecem 0 desenvolvimento das competências empreendedoras de proprietários-dirigentes em pequenas empresas. $\mathrm{Na}$ literatura revisada, identificaram-se três fatores pertinentes ligados ao comportamento empreendedor e três fatores pertinentes ligados à cognição do empreendedor. O método de pesquisa usado foi a pesquisa-ação, realizando uma intervenção de coaching junto a sete empreendedores ao longo de quatro meses. O objetivo da intervenção foi prover estímulos que favorecessem o desenvolvimento de competências empreendedoras. Foram realizadas entrevistas semiestruturadas com os empreendedores antes e após a intervenção. Tanto as entrevistas quanto as sessões de coaching foram gravadas e, depois, analisadas com técnicas de análise de dados qualitativos (Miles e Huberman, 1994). Os resultados revelaram que os fatores cognitivos favoreceram mais o desenvolvimento das competências empreendedoras do que os fatores de comportamento empreendedor. O estudo contribui ampliando a literatura útil para o entendimento detalhado do desenvolvimento de competências empreendedoras e o de seu caráter multifacetado.

Palavras-chave: Competências empreendedoras. Empreendedorismo. Pesquisa-ação. Coaching.

\section{ABSTRACT}

The purpose of this paper is to identify and understand factors that benefit the development of entrepreneurial competences in small business owner-managers. Literature presents three of those factors related to entrepreneurial behavior and three others related to entrepreneurial cognition. Research methods were based on action-research, using coaching interventions performed with seven entrepreneurs over four months. The objective of the interventions was to provide incentives to encourage the development of entrepreneurial competences. They included semi-structured interviews with the entrepreneurs before and after application of the coaching intervention. Both the interviews and coaching sessions were recorded and then analyzed with qualitative data analysis technics (Miles and Huberman, 1994). Results indicate that cognitive factors were more helpful to the development of entrepreneurial competences than entrepreneurial behavior. This study contributes enlarging the literature that is useful to understand the development of entrepreneurial competences and their multifaceted character.

Keywords: Entrepreneurial competences. Entrepreneurship. Action-Research. Coaching. 


\section{INTRODUÇÃO}

Estudiosos do empreendedorismo explicam que as competências empreendedoras são centrais para explicar o êxito no processo de desenvolvimento de um empreendimento (MITCHELMORE; ROWLEY, 2010). Contudo, ainda que muitas pesquisas abordem a temática das competências empreendedoras, pouco explicam sobre os fatores que determinam seu desenvolvimento. Por essa razão, o presente trabalho estuda tais fatores, fazendo-o com foco no caso dos dirigentes de pequenas empresas. Para tanto, o arcabouço teórico de apoio inclui estudos ligados ao empreendedorismo e à psicologia, os quais desenvolveram definições, teorias e caracterizações de competências empreendedoras, como fizeram McClelland (1987), Sarasvathy et al. (2003) e Rauch e Freese (2007).

Este artigo examina especificamente quais são os fatores que influenciam o desenvolvimento de competências empreendedoras de dirigentes de pequenas empresas, incluindo seis proposições de pesquisa. Assim, distinguiram-se dois grupos de fatores: (1) relativos ao comportamento empreendedor dos indivíduos e (2) aos aspectos cognitivos que envolvem a capacidade individual de pensar de forma empreendedora. Os fatores do primeiro grupo são visíveis por se expressarem em comportamento. Os fatores do segundo grupo são subjetivos, não diretamente observáveis, por ocorrem na mente dos empreendedores.

Os dados da pesquisa foram coletados ao longo de uma pesquisa-ação de quatro meses com sessões semanais de coaching. O delineamento da intervenção baseou-se nas recomendações de Jouison-Laffite (2009), que propõe cinco passos específicos a seguir, segundo um modelo cíclico de realização da pesquisaação em empreendedorismo. Ao todo, foram estudados sete empreendedores de três empresas diferentes. A coleta de dados se deu com entrevistas semiestruturadas realizadas antes e depois da aplicação da intervenção, as quais foram gravadas. As sessões de coaching também foram gravadas. A coleta de dados foi complementada por as anotações de campo do pesquisador e por entrevistas realizadas com os funcionários das empresas.

Os resultados mostram a tendência de os fatores cognitivos exercerem uma influência maior do que os fatores ligados ao comportamento empreendedor. Isso permite fazer uma reflexão sobre a relação de elementos cognitivos com o desenvolvimento de competências empreendedoras, sobretudo no tocante à autoanálise e à crença pessoal do empreendedor quanto a seu papel na empresa que dirige.

Este artigo está organizado em quatro partes. A primeira inclui uma revisão breve da literatura sobre competências empreendedoras e o desenvolvimento de seis proposições de pesquisa. Na segunda parte, descrevem-se o método de pesquisa e as empresas dirigidas pelos empreendedores pesquisados. $\mathrm{Na}$ sequência, são apresentados os resultados. O artigo conclui com uma discussão dos resultados, a identificação de limitações da pesquisa e pistas a indicação de possibilidades para pesquisas futuras. 


\section{REFERENCIAL TEÓRICO E PROPOSIÇÕES}

Compreender as competências empreendedoras e como se desenvolvem é relevante por elas serem alguns dos principais fatores que explicam o êxito de um novo empreendimento (SNELL; LAU, 1994; BIRD, 1995; MITCHELMORE; ROWLEY, 2010). Por competência entendem-se habilidades comportamentais como liderança, capacidade para desenvolver relacionamentos pessoais, valores e traços pessoais (McCLELLAND, 1973; SPENCER; SPENCER, 1993). A competência está associada a três eixos que formam a personalidade: aspectos pessoais (biografia e socialização), formação educacional e experiência profissional (LE BOTERF, 1995). Esses três eixos revelam a característica individual e singular do processo de desenvolvimento de competências, afinal esses eixos dificilmente seriam iguais em pessoas diferentes.

Estudiosos do empreendedorismo explicam que as competências empreendedoras são diferentes do construto das competências executivas estudadas em fenômenos organizacionais ligados à administração. $A$ diferença se dá sob três aspectos. $O$ primeiro refere-se às características pessoais de aos traços e habilidades de um empreendedor. De acordo com a literatura, traços e habilidades de um executivo de empresas tendem a ser diferentes dos de um empreendedor. O executivo de empresas normalmente está voltado para tarefas e metas racionalmente delineadas, além de normalmente não ser o dono do negócio, ao passo que um empreendedor busca reconhecer oportunidades, assumir riscos, ter disposição para gerir um negócio e desenvolver comprometimento com o desenvolvimento da empresa (McCLELLAND, 1987; JOHNSON; WINTERTON, 1999).

O segundo aspecto refere-se a um resultado central que normalmente se busca usando-se as competências empreendedoras: o crescimento do negócio. No construto competência executiva, foca-se seu uso em etapas de trabalho, metas organizacionais ou de carreira. Por outro lado, no construto competências empreendedoras, entende-se que o empreendedor, em todas as suas ações, pensa sobre o crescimento da empresa como um todo ((LE BOTERF, 1995). Isso mostra que nas competências empreendedoras considerase um foco mais amplo para uso da subjetividade do ator. Por essa razão, há autores que incluem nas características das competências empreendedoras elementos cognitivos como visões e imagens pessoais (BIRD, 1995).

O terceiro aspecto a marcar diferenças refere-se aos tipos de comportamento expressados. O construto da competência, no âmbito organizacional, é baseado em estudos sobre líderes de sucesso com comportamentos capazes de promover mudanças organizacionais e inspirar um melhor desempenho nos membros da empresa. Já as competências empreendedoras baseiam-se em estudos que buscaram identificar comportamentos que impactam no êxito de um empreendimento tais como a criatividade para desenvolver um negócio e a habilidade de preparar e elaborar um plano de negócio. Esses comportamentos são mais usais no âmbito do desenvolvimento de empresas (fenômeno empreendedor) do que na rotina organizacional de um executivo de empresa. (MITCHELMORE; ROWLEY, 2010). 


\section{Comportamento empreendedor e desenvolvimento de competências empreendedoras}

O desenvolvimento de competências empreendedoras está ligado, pelo menos em parte, ao comportamento empreendedor. Este pode ser fator motivador, como a necessidade de realização pessoal através do negócio, como um elemento motivacional que ajuda a descrever o comportamento empreendedor e influencia no desenvolvimento de competências empreendedoras (RAUCH; FRESE, 2007). A necessidade de realização pessoal é associada ao desenvolvimento de comportamentos que promovem o desenvolvimento de um novo negócio, como assumir responsabilidade pessoal pelo desempenho, tendência para estabelecer metas desafiadoras, iniciativa para pesquisar o ambiente, persistência e inovação (McCLELLAND, 1967; 1987). Esses comportamentos, segundo Man, Lau e Chan (2002), podem ensejar o desenvolvimento de tipos diferentes de competências empreendedoras, tais como formar redes de relação, identificar oportunidades e administrar eficientemente a empresa.

Então, é razoável sugerir que a necessidade de realização pessoal por meio do negócio gera no empreendedor uma predisposição interna que o faz sair de sua zona de conforto, para desenvolver novas habilidades e assumir comportamentos diferentes, resultando no desenvolvimento de competências empreendedoras. Há, assim, um aspecto psicológico e emocional no fenômeno de desenvolvimento de competências empreendedoras, na medida em que o empreendedor atua para atender seus anseios pessoais (McCLELLAND, 1987). Na forma de proposição conceitual, propomos que:

Proposição 1. Competências empreendedoras são desenvolvidas quando emerge no empreendedor a necessidade de sentir-se realizado pessoalmente desenvolvendo sua própria empresa.

As competências empreendedoras têm sido definidas de formas diversas, mas complementares. Por exemplo, Snell e Lau (1994) definiram-nas como o conjunto de conhecimentos, habilidades, qualidades pessoais, atitudes, visões, motivações e direcionamentos que podem se combinar de diversas maneiras e impactar positivamente no crescimento do negócio. Man, Lau e Chan (2002) explicam que se tratam de habilidades exercidas pelo empreendedor para desenvolver um trabalho com sucesso, objetivando o êxito de seu empreendimento. Mais relacionadas com aos comportamentos usuais do empreendedor, Mamede e Moreira (2005) referem-se às competências empreendedoras como capacidades para identificar oportunidades, construir redes de relacionamento, lidar com situações complexas, gerir, avaliar cenários estratégicos e comprometimento com os interesses individuais e organizacionais. E Rauch e Frese (2007) introduzem um elemento mais proativo ao definirem as competências empreendedoras como os traços pessoais que relevantes para o êxito de um empreendimento, tais como: inovação, proatividade, tolerância ao estresse, autoeficácia, autonomia e lócus de controle interno.

Assim, as definições de Snell e Lau (1994) se relacionam com os entendimentos de Rauch e Frese (2007) da seguinte forma: habilidades, qualidades pessoais e atitudes podem ser consideradas como traços pessoais que se caracterizam como sendo empreendedores quando há o direcionamento desses elementos para a criação e desenvolvimento de um empreendimento. Nesse ponto, pode-se também mencionar a definição de Man, Lau e Chan (2002), que entenderam as competências empreendedoras como a habilidade 
de se realizar um trabalho com sucesso, o qual pode influenciar no êxito de um empreendimento. Diante do exposto, pode-se entender que habilidades, qualidades pessoais e atitudes - elementos da personalidade representam um segundo fator que pode impactar no desenvolvimento de competências empreendedoras. Para tanto, é necessário que exista no empreendedor a vontade de moldar suas características para adotar comportamentos que sejam úteis para criar ou expandir seu empreendimento. Formalizando-se a segunda proposição de pesquisa, tem-se que:

Proposição 2. Competências empreendedoras são desenvolvidas quando o empreendedor direciona suas características pessoais (conhecimentos, habilidades, atitudes) para criar, desenvolver ou transformar sua própria empresa.

É oportuno destacar que as noções de Mamede e Moreira (2005) e Rauch e Frese (2007) apresentam tipos diferentes de competências empreendedoras, respectivamente para: construir redes, lidar com cenários complexos, avaliar, gerir cenários complexos e comprometimento individual e organizacional, assim como usar proatividade, tolerância ao estresse e autonomia. Para chegar a esses tipos, os autores basearam-se em estudar empreendimentos de sucesso. Os tipos tomaram por referência os comportamentos ocorridos ao longo do processo de criação e desenvolvimento de empreendimentos. Assim, é razoável sugerir que o processo de criação ou de desenvolvimento de uma empresa é um fator que parece influenciar o desenvolvimento de competências empreendedoras. Então, apresenta-se a terceira proposição de pesquisa:

Proposição 3. O processo de criação ou desenvolvimento do empreendimento influencia o desenvolvimento das competências empreendedoras.

\section{Características cognitivas e o desenvolvimento de competências empreendedoras}

Características cognitivas, que são aspectos da subjetividade do empreendedor, também se mostram na literatura como determinantes do desenvolvimento de competências empreendedoras. Este tende a ocorrer por mudanças nas ações e comportamentos do empreendedor (MARKOWSKA, 2011) justamente como resultado de mudanças em sua cognição (BIRD, 1995).

A literatura identifica cinco constructos basilares que compõem a cognição humana: as crenças, as crenças sobre si próprio, a crença sobre o controle de ação, os objetivos e a aprendizagem. As crenças, segundo Krueger (2007), são pressuposições individuais, profundamente enraizadas, que formam filtros perceptivos sobre como o mundo funciona, dando sentindo às experiências individuais e influenciando em tomadas de decisão. Ou seja, as crenças explicam ao menos parcialmente a maneira como o empreendedor lê e interpreta a realidade, além de como ele toma decisões com relação ao seu contexto.

A crença sobre si está associada à forma como o empreendedor enxerga a si mesmo. A partir dessa autopercepção, significados podem ser internalizados, auxiliando a explicar o papel a ser desempenhado por ele em seu contexto social (STRYKER; OWENS; WHITE, 2000). Em outras palavras, tal crença tem como foco central a autopercepção individual, que serve de base para o empreendedor entender o papel que tem a desempenhar em seu contexto social. Por sua vez, a crença sobre o controle de ação é um conceito 
desenvolvido por Sarasvathy, et al. (2003). Essa crença refere-se à confiança do empreendedor em ser capaz de realizar ideias e visões que imagina. Outro constructo basilar, os objetivos, conecta-se às forças motivacionais que o empreendedor emprega para realizar o que almeja. Esse é mais um aspecto das diversas motivações que movem o empreendedor, assim como a necessidade destacada acima de realização pessoal desenvolvendo seu próprio negócio. Já a aprendizagem refere-se à disposição e à flexibilidade do empreendedor para adquirir novos conhecimentos e desenvolver a postura necessária para realizar seus objetivos.

Isso posto, vê-se que a cognição está ligada ao desenvolvimento de competências empreendedoras e que questões ligadas ao universo subjetivo do empreendedor, como crenças, autopercepção individual e confiança no controle de ação, são relevantes nesse contexto. Assim, a crença pessoal que o empreendedor tem de si, levando em conta seu papel e sua confiança de que vai atingir um resultado desejado, tem impacto relevante no desenvolvimento de competências empreendedoras, razão pela qual apresenta-se a proposição a seguir.

Proposição 4. Crenças individuais sobre a autopercepção do empreendedor diante do contexto da empresa influenciam o desenvolvimento de suas competências empreendedoras.

Uma vez mais sobre os objetivos, eles são, segundo Skinner (1995), forças motivacionais que o empreendedor desenvolve para ter energia e seguir um direcionamento julgado necessário para realizar o que pretende alcançar. As motivações podem ser de diferentes naturezas, como, por exemplo, construir patrimônio pessoal, proporcionar um elevado padrão de vida à família, realizar viagens, entre outras - mas o crucial é que geram ações. Portanto, avançamos uma proposição mais:

Proposição 5. Motivações pessoais decorrentes da vontade de atingir objetivos para o empreendimento influenciam positivamente o desenvolvimento de competências empreendedoras.

Quando se trata das interações da aprendizagem com aspectos motivacionais para se empreender, é pertinente lembrar que ela pode ser entendida como a aquisição de novos conhecimentos necessários para se atingir um objetivo almejado (DWECK, 1986). Para esse autor, a aprendizagem inclui a flexibilidade para se adotar, quando necessário, posturas diferentes daquelas que foram inicialmente delineadas na mente, com o intuito de se atingir o objetivo desejado. Sendo que o construto da aprendizagem pode estar associado ao construto da competência empreendedora (MAN; LAU; CHAN, 2002). Parece ser, então, apropriado propor que:

Proposição 6. A aprendizagem influencia positivamente o desenvolvimento de competências empreendedoras. 


\section{MÉTODO}

A pesquisa caracterizou-se como exploratória (SELLTIZ et al., 2004) e o rito metodológico adotado foi o da pesquisa-ação. Lewin (1946) explicou que numa pesquisa-ação o pesquisador interage com a realidade social mudando-a simultaneamente enquanto a pesquisa é desenvolvida. Daí se explica o nome do método, ou seja, a união das palavras pesquisa e ação. Neste estudo, a pesquisa-ação baseou-se na intervenção com sessões de coaching realizadas com sete empreendedores de três diferentes empresas ao longo de quatro meses. Ao todo foi possível realizar 15 sessões de coaching em cada uma das empresas estudadas, que ocorreram com periodicidade semanal.

O delineamento da intervenção seguiu as recomendações de Jouison-Laffite (2009) sobre como conduzir o processo com cinco etapas de pesquisa-ação: (1) diagnóstico, com o qual se identificam problemas e causas; (2) planejamento, processo com que se consideram as possíveis formas de se resolver os problemas; (3) realizar a ação, aplicação da intervenção propriamente; (4) avaliar, estudar as consequências da ação, e (5) especificar as aprendizagens, momento no qual são identificados os resultados obtidos.

Ao longo da pesquisa foram realizadas uma avaliação inicial e uma avaliação final com os empreendedores que participaram do processo, permitindo efetivamente identificar se houve o desenvolvimento de competências empreendedoras.

Essa avaliação se deu com duas entrevistas individuais realizadas com os empreendedores antes de se iniciar a intervenção de coaching, a qual foi somada às notas de campo realizadas pelo pesquisador que aplicou o coaching. Depois, no final da intervenção, foi realizada uma entrevista final com cada um dos empreendedores buscando-se colher a avaliação de cada empreendedor sobre o desenvolvimento de competências empreendedoras ao longo da pesquisa-ação. Também foram realizadas, no início e no final da intervenção, entrevistas com os funcionários das empresas.

\section{Amostra}

Os critérios adotados para caracterizar o dirigente de empresa estudado como empreendedor basearem-se em Lima (2001) que destacou duas características fundamentais que configuram a figura de um empreendedor: (i) propriedade e gestão independente de qualquer outra empresa, e (ii) administração personalizada. Ao longo do processo de pesquisa foi possível identificar sete empreendedores que apresentam essas características. Quanto à definição de empreendedor utilizada para caracterização das pessoas estudadas adotou-se as ideias de Hirisch (1990) e Bessent e Tidd (2009). Para esses autores o empreendor é uma pessoa criativa e com noções de inovação para gerar algo de valor, dedicando tempo e esforço, assumindo riscos financeiros, para obter recompensas financeiras e satisfação pessoal.

No Quadro 1, são apresentados os empreendedores e as respectivas empresas por eles dirigidas. Entre os sete empreendedores há duas equipes de direção formadas por três proprietários-dirigentes de cada uma das empresas. E há uma empreendedora que dirige sozinha a sua empresa. 
Quadro 1: Características das empresas estudadas

\begin{tabular}{|c|c|c|c|c|}
\hline $\begin{array}{c}\text { Empreendedorl } \\
\text { Idade }\end{array}$ & Empresa & $\begin{array}{c}\text { Ramo de } \\
\text { atividade }\end{array}$ & Ano de fundação & $\begin{array}{c}\text { Faturamento mensal } \\
\text { estimado }^{\text {a }}\end{array}$ \\
\hline $\begin{array}{c}\text { Sarah/35 anos } \\
\text { Roberto/37 anos } \\
\text { Peter/38 anos }\end{array}$ & Happypromo & $\begin{array}{c}\text { Marketing } \\
\text { promocional }\end{array}$ & 2012 & $\mathrm{R} \$ 50.000,00$ \\
\hline $\begin{array}{c}\text { Alberto/63 anos } \\
\text { Carlos/34 anos }\end{array}$ & $\begin{array}{c}\text { Rocha } \\
\text { Arames }\end{array}$ & $\begin{array}{c}\text { Comércio de } \\
\text { arames }\end{array}$ & 1998 & $\mathrm{R} \$ 190.000,00$ \\
\hline Bernardo/38anos & Fisio & $\begin{array}{c}\text { Clínica de } \\
\text { fisioterapia }\end{array}$ & 2000 & $\mathrm{R} \$ 190.000,00$ \\
\hline
\end{tabular}

a Estimativa em balancetes financeiros e informações de faturamento apresentado pelos empreendedores.

Fonte: Dados da pesquisa.

\section{Coleta e análise dos dados}

Todas as entrevistas e sessões de coaching foram gravadas em gravador e transcritas. Foi feita análise em profundidade dos dados obtidos com o auxílio do software Atlas.ti. Para aferir se houve o desenvolvimento de competências empreendedoras, buscou-se identificar mudanças no comportamento dos empreendedores, seguindo as orientações identificadas na teoria revisada que explica que uma competência nova é possível de ser aferida através de novos comportamentos voltados para o desenvolvimento do empreendimento (BIRD, 1995; MARKOWSKA, 2011). Para tanto, na análise dos dados foram desenvolvidos códigos que pudessem ajudar a mapear os comportamentos dos empreendedores e identificar o surgimento de novos comportamentos. Também foram criados códigos de análise específicos que pudessem ajudar a identificar os fatores que influenciaram o desenvolvimento das competências empreendedoras, seguindo procedimentos recomendados por Miles e Huberman (1994).

Conforme se verá na apresentação dos resultados adiante, não foi possível identificar um fator de influência que tenha estimulado o desenvolvimento de competências empreendedoras de todos os empreendedores estudados. Razão pela qual na apresentação dos resultados são apresentados os empreendedores que foram estimulados pelo fator específico analisado, seguida de uma explicação sobre os motivos daquele fator não ter estimulado os demais empreendedores.

\section{Detalhamento da intervenção do coaching}

O desenvolvimento de competências empreendedoras com sessões de coaching demandou ao coach (e pesquisador) um delineamento específico para cada empreendedor. Afinal cada empreendedor apresentava uma necessidade individual de desenvolvimento de competências empreendedoras. Nas entrevistas iniciais, foram diagnosticadas as necessidades de desenvolvimento dos seguintes aspectos psicológicos e cognitivos: autoestima, saber trabalhar em equipe, compreensão do que é ser empreendedor, visão estratégica, foco no cliente e abertura para novos conhecimentos. 
O diagnóstico permitiu que fosse feito um planejamento de sessões direcionado para o desenvolvimento desses aspectos, os quais, segundo a fundamentação teórica e a avaliação do coach, eram necessários para o desenvolvimento de competências empreendedoras. Em cada sessão, foi utilizada uma ferramenta de coach específica, como: perguntas poderosas (CATALÃO e PENIN, 2011), meta esperta (ferramenta disponibilizada nos treinamentos da Sociedade Latino Americana de Coaching), o texto Jogue fora a sua vaquinha (CATALÃO e PENIN, 2011) e níveis de aprendizagem baseado no trabalho, de Lundeman e Erlandson (2004).

À medida que foram feitas as intervenções e observadas as consequências em termos de desenvolvimento das competências empreendedoras, constatou-se a adoção de novas posturas por parte dos proprietários-dirigentes, o que possibilitou também identificar processos de aprendizagem e expansão de consciência. Isso significava que os estímulos do coaching estavam contribuindo para o desenvolvimento individual de competências empreendedoras. É importante explicar que no caso de duas das empresas, Happypromo e Rocha Arames, foram realizadas sessões individuais e sessões coletivas. O motivo é porque eram empresas que possuem uma equipe de direção. Assim, foi mais adequado tratar coletivamente do desenvolvimento de assuntos ligados à visão estratégica, foco no cliente e abertura para novos conhecimentos.

A estratégia de aplicação do coaching em todas as sessões estava baseada em estimular um diálogo agradável e espontâneo com cada proprietário-dirigente, fazendo com que expressassem seu ponto de vista sobre cada um dos assuntos, e buscassem em sua experiência pessoal e em seus conhecimentos planos e soluções para os desafios vivenciados na empresa. Em cada sessão, o coach buscou associar a solução estabelecida em acordo com o empreendedor com alguma competência empreendedora. Assim foi possível vincular o conteúdo de cada sessão de coaching com o foco central da intervenção da pesquisa-ação. 


\section{ANÁLISE E RESULTADOS}

Segue a análise dos dados combinada ao tratamento de cada uma das seis proposições de pesquisa apresentadas.

\section{Necessidade de autorrealização}

Apenas dois empreendedores, da Happypromo, revelaram explicitamente que o desenvolvimento da empresa foi o resultado de um anseio pessoal associado ao crescimento individual e à aplicação de conhecimentos. Essa vontade de autorrealização criando uma empresa ficou bem expressa.

Estava cansado de ser empregado. Achei que tinha chegado o momento de ter meu próprio negócio e aplicar todo o conhecimento e experiência que eu tinha para criar a minha empresa. (Roberto)

Montar a agência foi uma oportunidade para eu poder criar uma empresa diferenciada, para desenvolver uma cultura de trabalho que eu acredito que dá certo, mas não vi aplicada em outros lugares. Tudo isso é muito importante para mim. Saber que posso fazer uma empresa de forma diferente. (Sarah)

Mostraram-se presentes também as mudanças de comportamento que levam ao desenvolvimento de competências empreendedoras associadas ao fator necessidade autorrealização. Roberto, ciente que gerir uma empresa é diferente de ser um executivo de agência de publicidade (cargo que ocupava antes), passou a ser responsável pelas gestões financeira e administrativa da agência de publicidade. Eram funções de que não gostava, porém sabia que eram fundamentais para o desenvolvimento do negócio. Por sua vez, Sarah passou a ter uma atuação comercial, algo que não fazia antes de criar a Happypromo. Para realizar bem essa função, empenhou-se em frequentar com assiduidade os escritórios de clientes, fazer almoços de negócios e participar de reuniões de briefing.

Quanto aos demais cinco empreendedores estudados, foi possível identificar uma mentalidade semelhante na qual ter uma empresa própria não significava uma realização pessoal, mas sim apenas um meio de se obter um ganho financeiro. Para Alberto, Carlos e Bernardo, dirigentes da Rocha Arames, a empresa representava uma forma de se trabalhar no mercado de arames, que gerava pouco emprego, sendo comum existir pequenas empresas que comercializam o material. Já Peter, encontrava-se empregado quando foi convidado para fazer parte da direção da Happypromo. Porém, para ele, as atribuições que tinha eram as mesmas de seu emprego anterior. De modo diferente, para Patrícia, a Fisio representava o meio mais comum de um fisioterapeuta ter um emprego, montando sua própria clínica. Portanto, para esses empreendedores não foi possível identificar algum aspecto subjetivo de sonho ou vontade pessoal projetados nas empresas que dirigem. 


\section{Características da personalidade do empreendedor}

As características pessoais da personalidade dos empreendedores, devidamente direcionadas, influenciaram no desenvolvimento de competências empreendedoras.

Sempre gostei de falar e organizar reuniões. Aqui na empresa, eu tinha dificuldades para fazer isso. Mas, quando passei a me posicionar de maneira mais objetiva para discutir os problemas da empresa, passei a ser mais ouvido e respeitado. (Bernardo)

Gosto de conversar, perguntar e saber das coisas. Tenho curiosidade. No mercado de arames, eu quero saber tudo: quem está vendendo, quem está comprando, quem está importando... Tudo isso pode ajudar a desenvolver estratégias na hora de comprar e de vender. (Carlos)

Muitas pessoas dizem que sou uma pessoa comunicativa e simpática. Jamais imaginaria que isso poderia me ajudar na Clínica para atrair novos pacientes. Depois que comecei a fazer contatos com os médicos a quantidade de indicações aumentou. (Patrícia)

Bernardo, ao perceber que tinha aptidões de liderança, entendeu que poderia desenvolver um relacionamento com seus sócios e promover a gestão de seus funcionários de maneira mais madura. Para tanto, passou a controlar comportamentos de irritação e raiva, que costumavam ocorrer misturados a muita fala por parte dele, de modo que ninguém o entendia e muitos se ofendiam com ele. Passou a ser mais comedido, expressando-se com calma, segurança e objetividade. Antes, tratava dos problemas mais graves da empresa misturados às pequenas tarefas cotidianas de trabalho, o que ele enfim percebeu como inadequado, improdutivo e a causa de muita tensão. Então, passou a organizar reuniões de trabalho com seus sócios e com os funcionários. Isso fez com que passasse a ser mais respeitado e ouvido. Por sua vez, Carlos Rocha conseguiu direcionar sua característica pessoal de curiosidade para mapear informações sobre o mercado de arames. Esse novo comportamento ajudou a desenvolver estratégias de compra e venda de arames. Isso ajudou a aumentar o faturamento e a rentabilidade da empresa. Patrícia direcionou as características de simpatia e fácil comunicação para desenvolver redes de relacionamento com médicos ortopedistas, que passaram a indicar a seus pacientes os serviços de fisioterapia da Fisio, ajudando a aumentar o faturamento.

Quanto aos demais empreendedores, Sarah e Roberto já apresentavam alto nível de comprometimento pessoal com o desenvolvimento da Happypromo antes do início da intervenção de coaching. Esse comprometimento já fazia com que suas características pessoais estivessem direcionadas a competências empreendedoras. Assim, não foi possível identificar algum tipo de mudança de comportamento resultante do coaching associada ao fator das características de personalidade. O mesmo pode-se dizer sobre Peter, que apresentou pouca mudança de comportamento ao longo da intervenção. Alberto, por se tratar de um empreendedor com mais idade, em certos momentos da intervenção, apresentou resistência aos estímulos direcionados pelo coach. Isso atrapalhou o desenvolvimento de suas competências empreendedoras. 


\section{Processo de criação ou desenvolvimento de empresa}

O processo de criação ou desenvolvimento das empresas influenciou para o desenvolvimento de competências empreendedoras entre os proprietários das três empresas estudadas.

Depois que iniciamos o trabalho de coaching e colocamos foco no crescimento da agência, percebi que precisa melhorar a maneira como eu me relacionava com meus sócios. Passei a ouvir mais e a falar mais tranquilamente. Antes estava habituado a coordenar equipes. Compartilhar o comando é uma experiência nova. (Peter)

Entendi que, para darmos um passo à frente e aumentar o faturamento da empresa, era necessário melhorar o controle financeiro. Por isso, fizemos um planejamento para separar as contas pessoais dos sócios do dinheiro da empresa. (Alberto).

Sempre tive planilhas apenas para controle financeiro. Não havia elaborado um controle sobre o fluxo e o perfil dos pacientes. Entendi que isso era necessário. Com a ajuda do coach, elaborei uma planilha para mapear a quantidade e o perfil de nossos pacientes. Consegui entender melhor o perfil dos pacientes. (Patrícia).

Esses três relatos revelam novos comportamentos adotados pelos participantes. Por exemplo, Peter compreendeu que, para empreender com uma equipe de direção, é necessário saber compartilhar o poder e desenvolver um bom relacionamento interpessoal com os sócios. A postura que ele tinha antes com algumas características de autoritarismo gerava conflitos e desgastes.

Alberto Rocha passou a separar as contas que pagava para identificar quais pertenciam à empresa propriamente e quais eram contas pessoais dos sócios. Essa distinção ajudou definir um valor mensal de retirada a título de pró-labore dos sócios. Isso ajudou a identificar o real valor que a empresa tinha em seu fluxo financeiro para fazer investimentos em mercadorias.

Patrícia entendeu que não havia um mecanismo de controle que possibilitasse mapear o número e o perfil dos pacientes, e que era necessário ter algum tipo de controle. Desta forma, ela conseguiu ter uma visão mais detalhada dos pacientes e dos planos atendidos. Um dos resultados desse controle foi poder decidir acerca da exclusão do atendimento com certos planos de saúde que pagavam muito pouco pelos serviços da Fisio.

Não foi possível associar o processo de criação ou desenvolvimento de empresa como um fator de influência para os demais quatro empreendedores estudados (Sarah, Roberto, Carlos e Bernardo), isto se deve ao fato de que na análise dos dados, não foi possível constatar um novo comportamento dos quatro empreendedores influenciado por este fator. 


\section{Crenças individuais sobre a autopercepção do empreendedor diante do contexto da empresa}

A questão das crenças individuais sobre a autopercepção dos empreendedores diante do contexto da empresa pode ser considerada como o fator que mais se destacou entre os fatores de influência estudados para o desenvolvimento de competências empreendedoras. Com exceção de Peter e Sarah, todos os empreendedores estudados não se consideravam empreendedores, mas sim 'donos de empresa'. Para alguns, ser empreendedor era algo para pessoas famosas em razão do êxito de seus empreendimentos, como se vê a seguir:

Empreendedor? Eu? Não! Empreendedor é o Samuel Klein das Casas Bahia. (Alberto)

Não me vejo como um empreendedor. Exemplos de empreendedores para mim são o Steve Jobs e o Roberto Justus. (Roberto)

Empreendedor é uma pessoa que tem sucesso e ganha dinheiro com a sua empresa. Não dá para ser empreendedora com uma clínica de fisioterapia. (Patrícia)

Como é que eu posso me considerar um empreendedor se ainda moro de aluguel? Empreendedor é um cara que ganha bastante dinheiro com negócio dele. Não é o meu caso. (Carlos)

Com todas as dificuldades enfrentadas pela Rocha Arames desde a fundação em 1998, as perdas financeiras que tivemos, não posso dizer que sou um empreendedor. A empresa pouco cresceu ao longo desses anos. (Bernardo)

Esses relatos foram colhidos nas entrevistas iniciais que precederam o coaching. $\mathrm{O}$ teor dos relatos revela uma imagem, de certa forma, mitificada sobre o empreendedor, uma imagem distante do contexto individual e organizacional dos empreendedores estudados. A relevância dessa constatação se dá pelo fato de que a literatura revisada que diferencia as competências executivas de competências empreendedoras aponta que, para esta última, é necessário que as pessoas se entendam como empreendedoras para que possam passar com sucesso pelo coaching que estimule o desenvolvimento de competências empreendedoras.

Para tratar disso, nas sessões iniciais de coaching, foram apresentadas definições e noções sobre o que é ser empreendedor e suas características que ajudaram a 'desmistificar' as imagens de pessoas de sucesso e que acumularam fortunas. Isso contribuiu para que fosse desenvolvida a crença individual em cada um dos empreendedores estudados de que eles de fato eram empreendedores, e que o contexto organizacional em que se encontravam não era apenas de uma empresa para se ter um ganho mensal capaz de cobrir as despesas pessoais, mas sim a de estar à frente de um empreendimento e se adotar ações como aumentar participação de mercado, atender clientes, gerar empregos, entre outros. 
Em termos gerais, essa mudança de crença fez com que os empreendedores passassem a ganhar mais confiança para agir. $O$ aumento do nível de comprometimento também foi visível. Os empreendedores diminuíram o tempo que gastavam com questões alheias ao trabalho para passar a trabalhar mais e com mais afinco. Isso é confirmado pelas passagens que seguem:

Descobri que é importante ter um discurso coerente com as ações, passei a trabalhar mais. (Roberto)

As meninas (fisioterapeutas) aqui se tornaram mais profissionais, explicam mais as coisas aos pacientes (os processos da clínica, etc.). E eu consigo trabalhar com mais facilidade, fazer relatórios, planilhas. (Patrícia)

Consegui enxergar e implementar soluções para problemas que tínhamos há muito tempo. (Carlos)

Com mudanças da perspectiva psicológica, todos os sócios ficaram mais motivados e engajados. (Bernardo)

Sarah e Peter não foram influenciados pelo fator crença de ser empreendedor, pois já se consideravam empreendedores. Ambos tiverem negócios próprios e com êxito financeiro em experiências anteriores à criação da Happypromo.

\section{Motivações pessoais decorrentes da vontade de atingir novos objetivos para a empresa}

A vontade de promover o desenvolvimento das respectivas empresas pôde ser identificada para quatro dos empreendedores estudados.

Quero fazer a empresa crescer e mostrar para o mercado que não sou apenas um executivo, mas que também sou capaz de tocar um negócio de sucesso. $\quad$ (Roberto)

Quando penso na minha filha, que tem dois anos, tenho vontade de fazer a empresa crescer bastante, pois quero proporcionar uma educação de qualidade a ela. (Carlos)

Sempre quis ter sucesso na minha vida. Tenho um pouco de ambição e gostaria de provar para colegas de escola, que hoje são executivas, que também sou capaz de prosperar financeiramente. (Patrícia)

Quero mostrar a meu pai que sou uma empreendedora tão boa quanto ele. (Sarah)

Roberto e Patrícia mostraram uma motivação parecida. Queriam mostrar que o objetivo de desenvolver o empreendimento estava associado à vontade de mostrar em círculos de amigos e colegas de trabalho que eram capazes de empreender com sucesso. Essa energia influenciou para que passassem a adotar novos 
comportamentos, ligados aos cuidados necessários para manter boas as instalações físicas das respectivas empresas, bem como fazer o desenvolvimento de processos organizacionais que ajudassem a ter ganhos de eficiência.

Roberto criou um trâmite diário para agendamento e controle de pagamentos da Happypromo. Patrícia desenvolveu um programa de qualidade para recepção e orientação cuidadosa dos pacientes. Esse programa foi aplicado por ela e sua equipe de fisioterapeutas.

A motivação pessoal não foi um fator verificado para Alberto, em razão do mesmo se considerar uma pessoa de idade avançada e que achava que já tinha feito tudo o que tinha a realizar na vida. Ele não apresentava novas ambições. Peter enxergava o trabalho como um meio de ganhar a vida e não conseguia associar questões de sua intimidade individual com o desenvolvimento da empresa. De certa forma, Peter apresentava uma postura linear, a empresa apenas como um meio de ganhar a vida. Já Bernardo, desde a fase inicial da intervenção de coaching, pontuava que havia trocado a carreira de publicitário para trabalhar na empresa com seu pai (Alberto) e seu irmão (Carlos). Por isso, tinha muita vontade de contribuir para o desenvolvimento da empresa. Contudo, essa motivação foi desenvolvida antes da intervenção de coaching. Por isso, não pôde ser considerada.

\section{Aprendizagem}

Ao longo da intervenção da pesquisa-ação, foi possível identificar a ocorrência de processos de aprendizagem que influenciaram no desenvolvimento de competências empreendedoras. Pode-se dizer que as aprendizagens ocorreram como uma consequência do desenvolvimento da autopercepção de ser empreendedor, a qual estimulou a aquisição de novos conhecimentos e a adoção de novos comportamentos.

Tive que aprender sobre planejamento, planejar meu tempo e minhas tarefas. Do contrário, não conseguiria dar conta de todas as atribuições que tenho na agência. (Roberto)

Aprendi que, para se formar uma equipe de trabalho, é necessário que os integrantes comunguem valores e mentalidades. (Sarah)

Aprendi a me comunicar melhor e ser mais objetivo. Passei a falar mais do cerne dos problemas ao invés de ficar dando voltas e protelando. (Alberto)

Aprendi que, para desenvolver um empreendimento, é necessário ter uma conduta profissional e não se deixar levar pela emoção e eventuais mágoas que surgem no caminho. (Bernardo)

Descobri que é possível estabelecer objetivos e metas de médio e longo prazos para a clínica. Sempre foquei no curto prazo, mas agora tomo decisões levando em conta resultados de médio e longo prazos. (Patrícia) 
Os trechos anteriores apontam para a ocorrência de aprendizagens para cinco dos sete empreendedores estudados. A mudança de comportamento que eles tiveram a partir das aprendizagens, foi benéfica para o desenvolvimento dos respectivos empreendimentos da seguinte forma: Roberto passou a fazer planejamento e a controlar de maneira racional seu tempo e as tarefas que executava. Sarah teve uma mudança na maneira como desenvolvia o relacionamento interpessoal dentro da equipe de direção da Happypromo. Passou a entender elementos necessários para configuração e trabalho de equipe.

A aprendizagem de Alberto the foi benéfica para melhorar sua comunicação e ter mais sucesso na resolução dos problemas da Rocha Arames. Bernardo, por sua vez, teve uma aprendizagem que the ajudou a desenvolver uma postura mais profissional e madura diante do negócio, evitando lamentações e queixas por eventuais desentendimentos de relacionamento que são naturais no contexto de uma equipe de direção. Patrícia, na Fisio, conseguiu desenvolver uma competência empreendedora ligada a estratégia da empresa para estabelecer direcionamentos de médio e longo prazo.

Não foi possível identificar o desenvolvimento de competências empreendedoras associadas ao fator de aprendizagem no caso de Peter, pois, conforme já destacado, ele já se considerava um empreendedor. Em sua maneira de pensar, ele entendia que não tinha a empreender com a intervenção de coaching ou com o contexto a sua volta, mas que seus sócios deveriam aprender com ele.

\section{DISCUSSÃO E CONSIDERAÇÕES FINAIS}

Como os indivíduos desenvolvem competências empreendedoras, como identificam as competências necessárias, quais fatores de influência impactam no desenvolvimento de competências, o que buscam atingir, são aspectos de processo pouco explorados na literatura, mas cuja compreensão pode ser muito útil para o desenvolvimento da pesquisa e da prática em empreendedorismo. Também é relevante compreender como atuar para gerar estímulos e neste estudo usamos o contexto experimental de uma pesquisa-ação, que adotou a metodologia de coaching como uma ferramenta que gerou estímulos que fizeram emergir fatores que influenciaram no desenvolvimento de competências empreendedoras.

Portanto, este trabalho gera contribuições para o campo de pesquisa do empreendedorismo, especificamente no tocante à geração de conhecimentos que possibilitam compreender de maneira mais aprofundada o desenvolvimento de competências empreendedoras. A metodologia da pesquisa-ação utilizada é pouco aplicada por pesquisadores da área (Jouison-Laffite, 2009). Contudo, foi possível perceber que o uso dessa metodologia foi benéfico no contexto do desenvolvimento de competências empreendedoras, sugerindo-se aos pesquisadores do campo do empreendedorismo gerar mais conhecimento sobre o método para a produção de direcionamentos mais específicos sobre sua aplicação. Isso poderá tornar mais frutífera e frequente a adoção do método da pesquisa-ação em empreendedorismo.

Quanto aos dados analisados e resultados, revelaram que tanto os fatores ligados ao comportamento empreendedor quanto os associados à cognição influenciam positivamente na busca pelo desenvolvimento de competências empreendedoras. Ficaram especialmente salientes aspectos do foro cognitivo e especialmente no tocante à proposição de pesquisa 4, tendo-se observado que os empreendedores tinham uma crença individual de que não eram empreendedores. O fato de estarem à frente de uma empresa, na percepção deles, não os tornava empreendedores. Contudo, à medida que foram se identificando como 
empreendedores, ganharam mais convicção e vontade para dirigir o empreendimento.

As crenças individuais são relevantes para se adotarem novos comportamentos que podem ser considerados como empreendedores (Kruger, 2007; Stryker, Owens e White, 2000; Sarasvathy et al., 2003). Isso ocorreu depois que os empreendedores passaram a se enxergar de fato como empreendedores, não apenas "donos de empresa". Essa constatação é relevante, pois apenas dois dos sete empreendedores estudados tinham uma crença individual de serem empreendedores. Para os demais, a crença de ser empreendedor estava associada a uma pessoa que dirige uma grande empresa e que acumulou fortuna. Essa crença não favorecia o desenvolvimento de uma autopercepção de empreendedor. Assim, a confirmação da importância e a apresentação dos mecanismos do desenvolvimento de crenças individuais que possibilitem a criação de uma autopercepção de empreendedor são contribuições deste trabalho. Estes pontos não tinham sido identificados na literatura revisada e, na análise dos dados, mostraram-se relevantes para o desenvolvimento de competências empreendedoras.

A aprendizagem é outro fator cognitivo que também apresentou relevância na análise dos dados, pois quatro empreendedores demonstraram ter adquirido algum tipo de novo conhecimento, considerado necessário para se atingir um objetivo desejado. Nesse ponto, cabe esclarecer que o tipo de conhecimento adquirido foi conhecimento tácito. Nenhum dos empreendedores estudados foi fazer algum tipo de curso ou treinamento para desenvolver a competência desejada. Eles apenas tomaram consciência de que era necessário desenvolver uma nova competência e fizeram um esforço nas rotinas diárias para desenvolvê-la. Essa constatação é outra contribuição deste estudo para destacar que empreendedores aprendem de maneira tácita. Aqui os dados apoiam as ideias de Dweck (1986), para quem as aprendizagens estão relacionadas a novas posturas.

O fator cognitivo das motivações pessoais pode complementar o fator das características empreendedoras quanto à necessidade de realização pessoal. Esses dois fatores combinados mostram que os empreendedores podem apresentar diferentes motivações para iniciar um processo de criação ou desenvolvimento de um empreendimento. Contudo, os dados apontam que apenas dois empreendedores apresentaram a necessidade de realização pessoal como uma motivação. Portanto, no contexto deste estudo, este fator não pode ser considerado de grande relevância e isso contraria parte da literatura revisada (McCLELLAND, 1987).

Quanto aos dois demais fatores ligados ao comportamento empreendedor, os dados apontaram que três entre os sete empreendedores estudados apresentaram desenvolvimento de competências empreendedoras. Isso mostra que os fatores cognitivos foram identificados com mais frequência do que os fatores ligados ao comportamento empreendedor.

Também cabe destacar que os dados confirmam a literatura revisada no tocante à associação positiva entre desenvolvimento de competências empreendedoras e crescimento da empresa (SNELL; LAU, 1994; BIRD, 1995; MITCHELMORE; ROWLEY, 2010). As três empresas dirigidas pelos empreendedores estudados aprimoraram seus processos internos e, inclusive, obtiveram um incremento no faturamento conforme seus dirigentes foram adotando ações empreendedoras. 


\section{Limitações e pesquisas futuras}

Este trabalho tem limitações. Primeiro, as usuais limitações inerentes ao método da pesquisa-ação, mesmo que tendo sido estudadas sete empreendedores, as conclusões não são generalizáveis. Os dados obtidos são pertinentes para o contexto dos empreendedores estudados. O tempo e a aplicação da intervenção, quatro meses com 15 sessões de coaching, é outra limitação. Possivelmente uma intervenção mais longa poderia gerar resultados diferentes que poderão gerar mais entendimentos sobre os fatores que influenciam no desenvolvimento de competências empreendedoras. Esse esforço considera-se válido pois, no presente estudo, já foi possível verificar que a intervenção de coaching foi capaz de favorecer o desenvolvimento de competências empreendedoras.

Com relação a futuras pesquisas, seria oportuno gerar mais conhecimentos sobre a questão da crença individual do dirigente de empresa e sua autopercepção enquanto empreendedor. Assim se terá uma maior riqueza de dados sobre o quanto um dirigente de empresa se percebe ou não como um empreendedor.

Também seria oportuna a realização de pesquisas que repliquem em parte ou integralmente o presente estudo para se gerarem conhecimentos no tocante aos fatores de influência para o desenvolvimento de competências empreendedoras - para se compararem novamente os fatores ligados ao comportamento empreendedor com os fatores ligados à cognição e se verificarem os resultados obtidos. Isso se justifica, pois o conhecimento gerado poderá ajudar no aprimoramento de instrumentos de intervenção benéfico a um espectro mais amplo de empreendedores, negócios e pesquisas.

\section{REFERÊNCIAS}

BESSANT, J.; TIDD, J. Inovação e Empreendedorismo. Porto Alegre: Bookman, 2009.

BIRD, B. Towards a theory of entrepreneurial competency: Advances in entrepreneurship. Firm Emergence and Growth, v. 2 , n.1, p. 51-72, 1995.

CATALÃO, J.; PENIN, A. Ferramentas de Coaching. 4. Ed. Lisboa-Porto: Libel, 2011.

DWECK, C. Motivational Processes Affecting Learning. American Psychologist, n. 41, v. 10, p.1040-1048, 1986.

HISRICH, R. D. Entrepreneurship/ Intrapreneurship. American Psychologist, n. 45, v.2, p. 209-222, 1990.

JOHNSON, S.; WINTERTON, J. Management skills, skills task force research paper 3. Department for Education and Employment, London, 1999.

JOUISON-LAFFITTE, E. La rechere action: oubliée de la recherche dans le domaine de l'entrepreneuriat. Revue de l'Intrepreneuriat, v. 8, n. 1, p. 1-35, 2009.

KRUEGER, N. What lies beneath? The experiential essence of entrepreneurial thinking. Entrepreneurship Theory and Practice, v. 31, n. 1, p. 123-138, 2007.

LE BOTERF, G. De la compétence. Essai sur um attracteur étrange. Paris: Les Éditions d'Orgnisation, 1995.

LEWIN, K. Action research and minority problems. Journal of Social Issues, v. 2, n.4, p. 34-46, 1946.

LIMA, E. As definições de micro, pequena e média empresas brasileiras como base para a formulação de políticas públicas. Anais do II Encontro de Estudos Sobre Empreendedorismo e Gestão de Pequenas Empresas-EGEPE, 2001. p. 421-436, EGEPE, 2001.

LUDEMAN, K.; ERLANDSON, E. Coaching the alpha male. Harvard Business Review, v. 82, p. 58- 67, 2004.

MAMEDE, M.; MOREIRA, Z. Perfil de competências empreendedoras dos investidores portugueses e brasileiros: Um estudo comparativo na rede hoteleira do Ceará. Anais do XXIX Encontro Anual da Associação de Pós-Graduação e Pesquisa em Administração, Brasília, 2005.

MAN, T.; LAU, T.; CHAN, K. The competitiveness of small and medium enterprises: A conceptualization with focus on entrepreneurial competence. Journal of Business Venturing, v. 17, n. 2, p. 123-142, 2002. 
MARKOWSKA. M. Entrepreneurial competence development - Triggers, processes and consequences. Dissertação de mestrad apresentada no Jönköping International Business School. Jönköping University, 2011.

McCLELLAND, D. The achieving society. New York: Free Press, 1967.

McCLELLAND, D. Testing for competence rather than for intelligence. American Psychologist, v. 28, n.1, p. 1-14, 1973.

McCLELLAND, D. Characteristics of successful entrepreneurs. The Journal of Creative Behavior, v. 21, n. 3, p 219-233, 1987.

MILES, M.; HUBERMAN, A. Qualitative data analysis: An expanded sourcebook. 2 ed., Thousand Oaks: Sage, 1994.

MITCHELMORE, S.; ROWLEY, J. Entrepreneurial competencies: A literature review and development agenda. International Journal of Entrepreneurial Behaviour \& Research, v. 16, n. 2, p. 92-111, 2010.

RAUCH, A., FRESE, M. Let's put the person back into entrepreneurship research: A meta-analysis of the relationship between business owners' personality characteristics and business creation and success. European Journal of Work and Organizational Psychology, v. 16, n. 4, p. 353-385, 2007.

SARASVATHY, S.; DEW, N.; VELMURI S.; VENKATARAMAN, S. Three views of entrepreneurial opportunity. In ACS, J; AUDRETSCH, D. (Eds.), Handbook of Entrepreneurship Research: An Interdisciplinary Survey and Introduction. New York: Kluwer, p. 141-160, 2003.

SELLTIZ, C., WRIGHTSMAN, L.; COOK, S. Métodos de Pesquisa nas Relações Sociais. 4 ed. vol. 1. São Paulo: EPU, 2004.

SKINNER, A. Perceived Control, Motivation, \& Coping. Thousand Oaks: Sage Publications, 1995.

SNELL, R.; LAU, A. Exploring local competences salient for expanding small business. Journal of Management Development, v. 13, n. 4, p.4-15, 1994.

SPENCER, L.; SPENCER, S. Competence at work: A model for superior performance. New York: John Wiley \& Sons, 1993.

STRYKER, S; OWENS, T. WHITE, R.. (Ed.). Self, identity, and social movements. University of Minnesota Press, 2000. 